\title{
Evaluation of catalysts derived from palm kernel shell carbon in a passive NOx removal from a diesel engine exhaust
}

\begin{abstract}
Carbon-supported de-NOx catalysts have attracted much attention lately due to their reactivity at low temperature, where it is usually challenging to remove NOx from mobile emission sources such as light-duty diesel-powered vehicles. In addition, passive mode of NOx removal system is preferable due to the absence of a reductant injection requirement, which could add an extra cost to the system. Palm kernel shell activated carbon (PKS) was used to synthesize SCR catalysts by precipitating manganese $(\mathrm{Mn})$ and/or cerium (Ce) oxides. The catalysts were characterized using nitrogen adsorption-desorption experiment, X-ray fluorescence analysis (XRF), hydrogen temperature-programmed reduction (H2-TPR) and Fourier-Transform infrared spectroscopy (FTIR). The experiment of NOx removal from a real diesel engine exhaust system revealed that $\mathrm{Mn} / \mathrm{PKS}$ exhibited the highest NOx removal at $74 \%$ and at the lowest temperature of $140{ }^{\circ} \mathrm{C}$. This was attributed to the high surface area and micropore volume, high metal loading, enhanced hydroxyl and carbonyl functional groups and the presence of reducible $\mathrm{MnO} 2$ species. Therefore, it is expected that this type of catalyst may serve as a cost-effective material for a sustainable alternative to the current practice in removing NOx from diesel engine vehicles.
\end{abstract}

Keyword: NOx removal; Passive mode; Carbon catalyst; Real diesel engine exhaust 